\title{
ADDRESS: SCENARIOS AND ARCHITECTURE FOR ACTIVE DEMAND DEVELOPMENT IN THE SMART GRIDS OF THE FUTURE
}

\author{
Eefje PEETERS \\ VITO - Belgium \\ Eefje.peeters@vito.be
}

François BOUFFARD

The University of Manchester - UK

francois.bouffard@manchester.ac.uk

\author{
Régine BELHOMME \\ EDF - France \\ regine.belhomme@edf.fr \\ Seppo KARKKAINEN
VTT - Finland
seppo.karkkainen@vtt.fi \\ Maarten HOMMELBERG \\ VITO - Belgium \\ maarten.hommelberg@vito.be
}

\author{
Carlos BATLLE \\ Universidad Pontificia Comillas - Spain \\ carlos.batlle@iit.upcomillas.es \\ Daan SIX \\ VITO - Belgium \\ daan.six@vito.be
}

\begin{abstract}
The ADDRESS European project aims to deliver a comprehensive commercial and technical framework for the development of "Active Demand" in the smart grids of the future. Specifically, ADDRESS is investigating how to effectively develop the participation of domestic and small commercial consumers in the power system markets and in the provision of services to the different power system participants.

After a brief overview of the project target, objectives and methodology, this paper focuses on the first project results regarding:

- The ADDRESS conceptual architecture, a description of its participants, the signals exchanged between them, and its associated markets and market interactions.

- The main concepts used to implement the architecture and to achieve the project objectives.

- A survey on country specific aspects giving insight into the current situation and the potential for the different aspects of the conceptual architecture.

- The scenario approach designed for the project.

- The flexibility capabilities of domestic and small commercial consumers.
\end{abstract}

\section{INTRODUCTION}

The ongoing developments in Information and Communication Technologies, advanced metering systems, energy management at the local level (houses, commercial buildings, etc.) as well as household technologies open new opportunities for demand side initiatives in the electricity business. At the same time, there is a growing need for a more active participation of demand in power systems, and consumers are increasingly concerned about environmental and energy efficiency issues.

In this context, the ADDRESS European project ("Active Distribution networks with full integration of Demand and distributed energy RESourceS") aims to deliver a comprehensive commercial and technical framework for the development of "Active Demand" (AD) in the smart grids of the future, or, in other words, for the active participation of domestic and small commercial consumers in the power system markets and in the provision of services to the different power system participants.

Having small consumers playing an active role in the markets around which power systems are currently organized is undoubtedly an outstanding issue. The challenges to tackle are multi-fold and of sometimes very different natures; examples are given in [1]:

- Technological issues: automation and communication infrastructures are needed to enable demand response, and to make a widespread end-user participation possible in support of grid and market operations.

- Economic and regulatory issues: the cost of the required infrastructure investment is currently difficult to justify. The necessary two-way communication systems must be motivated by more than just the end-use energy savings alone. The benefits of automatic meter reading and other utility-related functions must also be taken into account. Besides, retail rates and tariffs need to provide consumers with incentives for responding, and the wholesale market structure should be open for end-user participation.

- Acceptance issues: the system operators must have confidence in relying on demand side initiatives to support real-time grid and market operations, and consumers must be willing to modify the way they consume electricity. Additionally, the AD future relies critically on the characteristics and flexibility capabilities of physical loads and possible embedded generation in consumers' premises.

This paper first gives an overview of ADDRESS target, objectives and methodology. Then its first results are presented:

- A survey of European country specific aspects giving insight into the current situation and the potential for different aspects of $\mathrm{AD}$ development. This analysis is based on information collected on regulatory, technical, economic, socio-cultural and market contexts through a questionnaire in a number of European countries.

- The guidelines for design of the scenarios that will be used throughout the project. This scenario approach will 
determine success factors for ADDRESS and possible associated futures.

- A description of the proposed architecture, along with the main concepts that will be used for its implementation.

\section{TARGET, OBJECTIVES AND METHODOLOGY}

ADDRESS is a four-year large-scale R\&D European project launched in June 2008. The project coordinator is ENEL Distribuzione SpA and the consortium consists of 25 partners from 11 European countries spanning the entire electricity supply chain, qualified R\&D bodies, SMEs and manufacturers [2].

As already mentioned, the aim of the project is to develop a comprehensive commercial and technical framework for the development of Active Demand in the smart grids of the future. In ADDRESS, only domestic and small commercial consumers are considered, and both the loads and possible embedded generation at their premises will be taken into account. More specifically [2]:

- ADDRESS will develop technical solutions both at the consumers' premises and at the power system level to enable $\mathrm{AD}$ and to allow real-time response to requests from markets and/or from other power system participants.

- This implies identifying the possible barriers against AD deployment and proposing solutions to remove these barriers. Moreover, a scaleable and open communication architecture is needed to deal in real time with large numbers of consumers (hundred thousand and above).

- Complementarily, ADDRESS will identify the possible benefits of AD for the different power system participants and will develop appropriate contractual and market mechanisms for the exploitation of these benefits.

- In addition to technical and economic questions, ADDRESS will deal with regulatory, societal and cultural aspects and, in particular, the project will define recommendations to lower possible regulatory barriers, and will study accompanying measures in dealing with small consumers' socio-cultural and behavioural factors.

- The concepts and solutions will be validated in three different field test sites with different demographic and electricity supply characteristics in Spain, Italy and on a French island.

\section{SURVEY OF COUNTRY SPECIFIC ASPECTS}

This section gives a short overview of some of the main outcomes of the country specific aspects survey carried out. The scope of the survey was limited to the factors likely to be important for the implementation of AD in Europe over the coming decades. Namely, the level of future deployment of $\mathrm{AD}$ is influenced by factors, which are first economic and technical in nature. Second, factors, such as the regulatory or the level of environmental awareness in society, are more of political and socio-cultural natures. The survey demonstrated the following:
The large development of Renewable Energy Sources (RES) is expected to increase the need for AD services. There is a vast multiplicity of renewable energy sources. Among others, wind power is currently one of the most extensive generating renewable source, being remarkable the proportions that has been reached in Spain, Denmark and Germany. In this context, the additional aspect to take into consideration is to what extent RES are exposed to the true market price signals. Now, except in rare exceptions, no incentive is provided to small RES to manage neither their generation nor their imbalances.

Retailers will probably be key agents for the future of AD deployment, and at the same time, the AD business can be a key factor for retailer development. Retail markets all around Europe are still somewhat immature, switching levels are still small. The retail market structure is still highly linked to the distribution business where, in most of the countries, the current unbundling of retail and distribution is mostly legal and functional in nature.

Smart meters might be one of the key enablers for AD business development. Three groups of countries can be distinguished: the ones in which the regulator has already opted for defining minimum standards, the ones in which the initiative to install new advanced metering equipment has explicitly been left to the private sector and finally those that still have not taken any decision about it.

A high level overview of the low voltage networks of most European countries has been carried out, and it appears that the networks should be able to accommodate the ADDRESS concepts. However, significant investment will be required to provide the necessary communications, metering and control to allow the concepts to deliver value.

\section{SCENARIO APPROACH}

ADDRESS is developing a scenario approach to encompass better the vast diversity in the electricity business which can be seen across Europe. Specifically, the scenarios will explore how four or five "ADDRESS futures" may emerge and how successful these futures could be.

Unlike a great majority of recent scenario work in the electricity sector-for instance that of Ault et al. [3], which is based on the identification and variations in the intensity of key drivers for change going forward-, the scenario building methodology developed in ADDRESS is based on a totally different approach. Here the scenario approach focuses on charting the course for changes in the electricity supply chain leading to a variety of success targets (e.g. high, medium and low) in the horizon to 2020 envisioned by the European Technology Platform SmartGrids [4]. This approach, whereby scenarios are tied to success targets to be reached in the future, has the advantage of specifying the end boundary conditions of the future evolutions. From these, proper scenario narrative descriptions establish reasonably robust timelines of changes working back to today, that is, the starting boundary condition. 
Paper 0406-

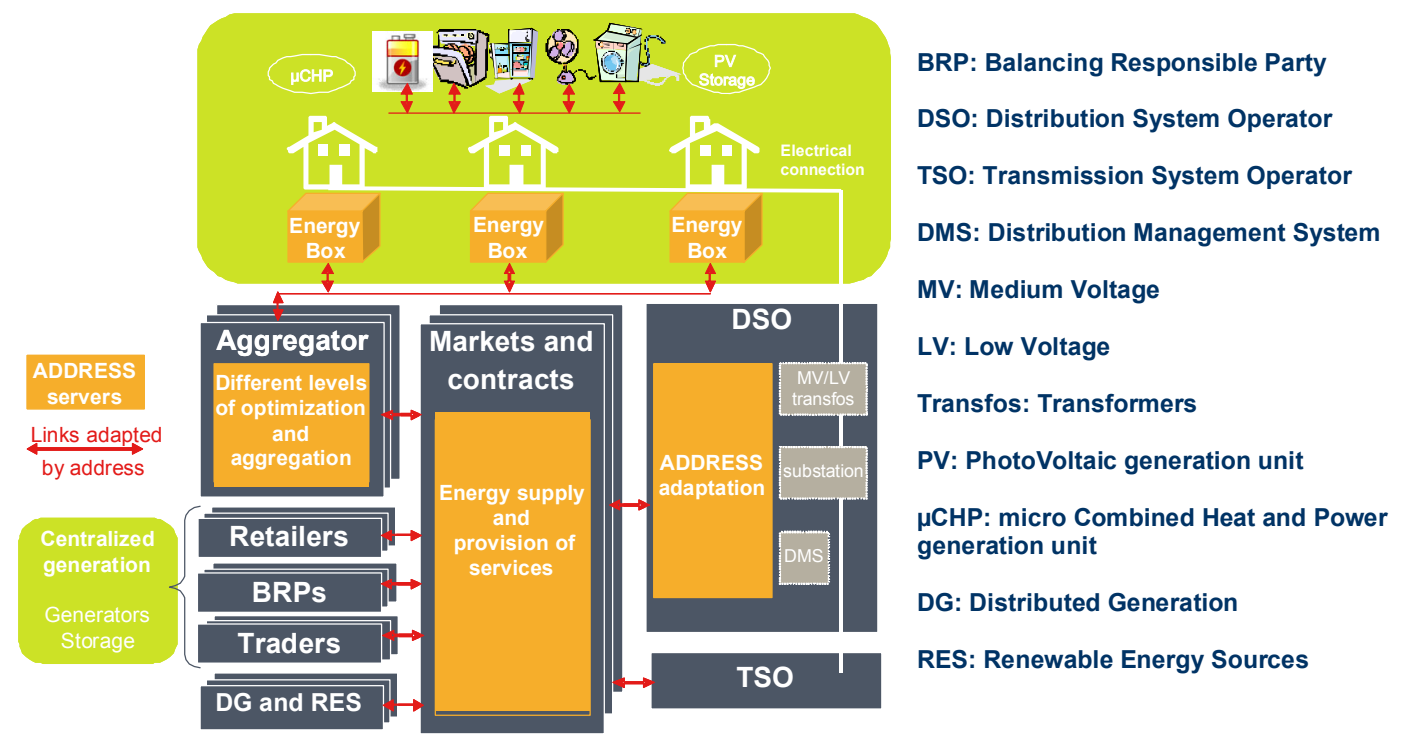

Figure 1 - ADDRESS conceptual architecture

The core of the scenario approach is the methodology for computing metrics for assessing the relative success of the ADDRESS futures. The metrics are objective quantitative mappings of a number of subjective qualitative expectations about positive and negative effects of AD over the significant actors of the supply chain and their respective stakes. There are essentially two challenges with this methodology: (1) one has to properly determine whether AD will have a positive or a negative effect on any given actor's stake, and (2) one has to "weigh-in" properly across the stakes and actors the relative importance of those effects. This is part of ongoing work involving close consultation with the wide range of consortium members making up the ADDRESS project team.

\section{ADDRESS CONCEPTUAL ARCHITECTURE}

Figure 1 shows the ADDRESS scope, along with its first conceptual architecture, building on the architecture developed in the FENIX European project [5].

In the proposed architecture, the aggregators are the key mediators between the consumers, the markets and the other power system participants. They play a central role:

- They collect the requests and signals for AD-based services coming from the markets and the different power system participants.

- They gather the "flexibilities" and the contributions provided by consumers to meet those service requests and signals and they offer them to the different power system participants through various markets.

At the consumer level, the Energy Box is the interface between the consumer and an aggregator. It carries out the optimisation and the control of the loads and local distributed energy resources at the consumer's premises. It "represents" the consumer from an aggregator's perspective.

The Distribution System Operators (DSOs) also play an important role because AD (as developed in the project) concerns consumers connected to distribution networks.
DSOs still continue to ensure secure and efficient network operations. They do so mainly through interactions with the other power system participants and, in particular, with aggregators via markets. Also, they maintain direct interactions with TSOs to ensure secure network operation.

In the project, development of algorithms and prototypes will be carried out in detail for the above three power system participants. The interactions with the other power system participants will be simulated using simplified models that include sufficient detail to allow the proper validation of the solutions.

The markets ("Markets and contracts" in Figure 1) consist of all kinds of commercial agreements between power system participants (such as bilateral contracts, forward markets, real-time markets, power exchanges). Markets for different products and services are considered:

- Energy supply

- Ancillary services in the form of steady state voltage control, tertiary frequency control and tertiary active power reserve

- Balancing services (and compensation of variability from RES)

- Overload and network congestion relief

- Load shaping services (and in particular peak shaving). Besides aggregation of demand, the following main concepts will be used to achieve the project objectives:

- The basis for the interaction between the power system participants is the exchange of real-time price signals and real-time volume signals (mainly energy- or power-based signals). "Real time" here means a time scale of 20 to 30 minutes ahead or longer (i.e. hourahead, day-ahead, etc.)

- Local optimisation is needed to determine and meet the requirements for the requested services. Those services may depend on the topology of the concerned network, the geographical location (local/regional) and can vary in time. Therefore, different levels and amounts of dis- 
tributed intelligence are required. The issue is to put the "right amount" of intelligence in the "right place." A new approach will be used to foster the flexibility and active participation of consumers: the so-called "Demand Approach". Domestic consumers do not have the same motivations, understanding or technology awareness as producers. Therefore, a different approach has to be taken to enable AD, implying appropriate technological development in the houses, accompanying measures to obtain consumers' engagement. The services consumers could provide are requested through the price and/or volume signal mechanisms and are provided on a voluntary and/or contractual basis.

\section{FLEXIBILITY OF DOMESTIC AND SMALL COMMERCIAL CONSUMERS}

ADDRESS involves all types of equipment installed at the consumer's premises: distributed generation (such as PV and micro turbines), thermal and electrical energy storage systems and electrical appliances (loads).

Typically, household cogeneration systems require high availability in order to be considered worthwhile. Thus, while the cogeneration systems with internal combustion engines meet the household's needs and are already widely available on the market, the micro-turbine systems and Stirling engines need further studies to make them more suitable for the current and future market's requirements. Regarding generation systems from RES (mainly PV and to a lesser extend small wind), their availability and flexibility is closely linked to the capability of coupling them with storage systems.

Energy storage systems in residential applications include systems that provide electric power output: "electricity-toelectricity" systems like capacitors or super-capacitors, "mechanical power-to-electricity" systems like flywheels, and electrochemical systems such as batteries and flow batteries. Thermal energy storage systems are used in heating and cooling systems. Thermal energy can be stored as sensible heat, latent heat and chemical energy.

For many loads and house appliances the following aspects were analysed: characteristics of the device, its usage and control, and energy impact of their flexibility capability.

From the flexibility point of view, air conditioners, water heaters and space heating systems have the highest potential although many other small appliances can also offer flexibility. On the other hand, the improvement of energy efficiency decreases the flexibility potential. Finally, in the future, the hybrid and electric plug-in vehicles are foreseen to provide high potential for flexibility.

\section{CONCLUSIONS}

After a brief overview of the ADDRESS European project, this paper gives the first results obtained regarding: (1) country specific aspects that give insight into the current situation and potential for different aspects of AD develop- ment; (2) guidelines for scenarios to use during the project and success targets to be reached in the future; (3) a description of the ADDRESS architecture and the main concepts that will be used throughout the project.

The active participation of domestic and small commercial consumers to the provision of services will be an essential ingredient for the smart distribution grids of the future. It will probably bring multiple benefits to the different power system participants. In this respect, ADDRESS presents a unique and timely opportunity to coordinate and combine the expertise and resources of partners from all over Europe in order to develop solutions capable both to foster this participation and exploit its benefits to the fullest. In particular, the project results are expected to contribute to:

- enabling real-time pricing for all network users,

- improving the security of supply of critical loads,

- increasing the efficiency, flexibility, safety, reliability and quality of the European power systems in the context of a more integrated European energy market.

The presented results are a "beginning" and not an "end". They give first elements on which to build the thinking and the further developments regarding ADDRESS concepts and solutions. They provide a common basis for the work that will be carried out in the other tasks of the project.

\section{ACKNOWLEDGEMENTS}

The research leading to the results has received funding from the European Community's Seventh Framework Program (FP7/2007-2013) under grant agreement $n^{\circ} 207643$. We would like to thank the following ADDRESS participants for their contributions: J. Su (University of Manchester), M. Sebastian (EDF), P. Lang (EDF Energy ), C. Yuen (ABB), J. Jimeno(Labein), A. Vicino (University of Siena), W. Fritz (Consentec), R. Cerero (Iberdrola), G. Valtorta (ENEL Distribution) and D. Hirst (RLtec).

\section{REFERENCES}

[1] A. Baitch, A. Chuang, G. Mauri, C. Schwaegerl, 2007, "International perspectives on demand-side integration", Proceedings of CIRED, Paper 0914.

[2] R. Belhomme, R. Cerero Real de Asua, G. Valtorta, A. Paice, F. Bouffard, R. Rooth, A. Losi, 2008, "ADDRESS - Active demand for the smart grids of the future", Proceedings CIRED Seminar 2008: Smart Grids for Distribution, Paper No. 0080.

[3] G. Ault et al., 2005, Electricity Network Scenarios for 2050, Supergen Futurenet Consortium, Glasgow, UK.

[4] European Commission, 2006, European Technology Platform SmartGrids: Vision and Strategy for Europe's Electricity Networks of the Future, Brussels, Belgium.

[5] M. Sebastian, J. Marti, P. Lang, 2008, "Evolution of DSO control centre tool in order to maximize the value of aggregated distributed generation in smart grid", Proceedings CIRED Seminar 2008: Smart Grids for Distribution, Paper No. 0034. 